https://doi.org/10.18800/iusetveritas.201703.014 (c) (i)

\title{
Legítima, ¿Pars hereditatis o pars bonorum?()
}

\section{Legitimate, ¿Pars hereditatis o pars bonorum?}

\author{
Benjamín Aguilar Llanos ${ }^{(*)}$ \\ Pontifica Universidad Católica del Perú
}

Resumen: El presente trabajo versa sobre la legítima como institución del Derecho Sucesorio y se centra básicamente en la discusión sobre si debe ser considerada como pars hereditatis o pars bonorum. En esa línea, vincula la legítima con la institución de la familia y cómo se puede ver una correspondencia entre a quiénes se les puede dar la herencia anticipada y quiénes pueden recibir la herencia. Asimismo, apoyándose en las normas nacionales el autor toma una postura al señalar que la legítima es pars hereditatis debido a que incluye solo a los herederos del causante. Finalmente, da más alcances sobre la legítima al explicar cómo se relaciona con la institución de la colación.

Palabras Clave:Legítima - Pars Hereditatis - Pars Bonorum - Derecho Sucesorio - Colación - Herederos Forzosos - Anticipo de Herencia

\begin{abstract}
This paper is about the legitimate as an institution of the Inheritance Law and it focus in the discussion over if it would be considered as a pars hereditatis or as a pars bonorum. Following that, the author links the legitimate with the family institution along with how it could be a correspondence between who can receive this inheritance anticipated and who could receive the inheritance. Likewise, backed on national legislation the author takes a stand saying that the legitimate is pars hereditatis because of includes the heirs only. Finally, the author give us more scopes regarding the legitimate while explains how it be related with the institution of collation.
\end{abstract}

Keywords:Legitimate - Pars Hereditatis - Pars Bonorum - Inheritance Law - Collation - Compulsory Heirs - Anticipated Inheritance

Sumario: 1. Introducción_2. Código Civil y la regulación de la legítima_3. Legítima nace en defensa de los familiares del causante_4. ¿Qué opina la doctrina sobre la legítima pars bonorum? _ 5. ¿Los legitimarios no

${ }^{*}$ Nota del editor: Este artículo fue recibido el 15 de octubre de 2017 y su publicación fue aprobada el 26 de noviembre de 2017.

${ }^{* *}$ ) Profesor de Derecho de Familia y Sucesiones en la Pontifica Universidad Católica del Perú. Correo electrónico: baguila@ pucp.edu.pe 
Legítima, ¿Pars hereditatis o pars bonorum? Legitimate, ¿Pars hereditatis o pars bonorum? necesariamente son herederos? _ 6. Según los partidarios de la legítima pars bonorum el legitimario no necesariamente es heredero o aún más categórico, el legitimario no es heredero_7. ¿La legislación vigente sobre la legítima admite la posibilidad de que los legitimarios no sean herederos del causante?_8. Legítima es pars hereditatis porque incluye solo a los sucesores del causante_9. Legítima, normas de orden público_10. La institución de la colación y la legítima_11. Conclusiones_12. Referencias bibliográficas.

\section{Introducción}

La institución de la legítima no es una figura reciente, sus orígenes se remontan a la época del derecho romano y germano, y allí se estableció a través de la querella de inoficiocidad del testamento, otros señalan, que debe su aparición a la cuarta falcidia, en ambos casos se trataba de conservar una parte del patrimonio del causante a favor de sus familiares más cercanos y directos, (los descendientes). En el primitivo derecho germano, sobre la base de la copropiedad familiar, la legítima representaba una licencia al causante para disponer solo de una parte del patrimonio, en tanto que lo demás era del grupo familiar.

En Perú, la legítima ha pasado a nuestro derecho actual, habiendo sufrido algunas modificaciones, como por ejemplo en el Código Civil (en adelante, "CC") de 1852, la cuota legitimaria era de cuatro quintos del patrimonio, dejándose para el causante un quinto de libre disposición; con el CC de 1936 y 1984, las cuotas legitimarias, son de dos tercios del patrimonio cuando se trata de descendientes o cónyuge, y la mitad cuando son ascendientes. Posteriormente se ha incluido como legitimario en defecto de cónyuge, al sobreviviente de la unión de hecho (Ley 30007), además de que hoy no solo son legitimarios, como en el derecho romano, los descendientes, sino también lo son los ascendientes en defecto de los primeros, y la cónyuge o si fuera el caso el sobreviviente de la unión de hecho.

El presente artículo pretende abordar la naturaleza jurídica de la legítima, y no tanto su justificación y permanencia, cuestión ampliamente debatida hoy en la doctrina, dejando sentada nuestra posición de que esta institución es necesaria, empero debe ser reestructurada para que cumpla su fin, cual es servir de apoyo a la familia del causante.
Así como existe debate sobre su permanencia o supresión de la institución, de igual forma existe discusión sobre si la legítima es pars hereditatis o pars bonorum; sobre el particular refiere Eva Polo Arévalo que la confusión entre los conceptos de legitimarios y heredero, provoca la dificultad por definir qué se entiende por legítima y su naturaleza, ya que la literalidad del precepto podría concluirse que ésta se configura como una pars hereditatis por atribuirle al legitimario la cualidad de heredero forzoso teniendo por tanto una parte alícuota de la herencia (en Perú en efecto la definición de la legítima nos lleva a esa conclusión), sin embargo señala Eva Polo que la doctrina mayoritaria (mencionando a Roca Sastre, García Valdecasas, Valet de Goytizolo) conceptúa la legítima como pars bonorum por lo que el legitimario no necesariamente tiene que ser heredero (2013).

El legislador peruano define la legítima como la parte de la herencia de la que no puede disponer libremente el testador cuando tiene herederos forzosos (artículo 723 del CC), ello implica, según el CC ubicar la legítima en sede testamentaria, lo que se reafirma cuando regula la institución en el título de sucesión testamentaria, empero ello no termina siendo cierto, porque la legítima también tiene presencia en sede de sucesión intestada.

Sin embargo, el tema en cuestión radica si la legítima efectivamente es parte de la herencia del causante como lo define el código civil, o si es un valor de los bienes y derechos que pueden ser pagados a título de legados, o liberalidades otorgadas en vida del causante todo ello como expresión de la voluntad del causante, e incluso los legitimarios no necesariamente terminarían siendo herederos.

La primera fórmula para considerar la legítima como pars hereditatis es decir parte de la herencia, es una postura seguida entre otros, por los códigos de Chile y Colombia, cuando 
Benjamín Aguilar Llanos

afirman que la legítima es parte de la herencia y que los legitimarios son herederos.

\section{Código Civil y la regulación de la legítima}

Cierto es que no hay mucha precisión e incluso hay confusión no solo al definir la institución, sino igualmente al referirse sobre qué recae la legítima; sin embargo, de ello no podemos deducir que la legítima sea pars bonorum.

En efecto, cuando en el artículo 723 del CC se define la legítima, ésta se trata en el título de sucesión testamentaria, induciendo al error de suponer que la institución solo aparece en este tipo de sucesión cuando ello no es lo correcto, en tanto que la legítima se da en sucesión testamentaria como en la intestada; por otro lado, y confirmando esta invitación a la confusión, el legislador al definir la institución alude al testador, esto es remitirnos solo a la sucesión testamentaria. Sin embargo, el error mayor es confundir sobre qué recae la legítima, así en el artículo 723 se señala que es parte de la herencia, luego en el numeral 725,726 y 727 del CC se alude a parte de los bienes del causante; entonces, se genera una confusión si las cuotas legitimarias deben obtenerse del patrimonio hereditario (herencia) donde existen bienes, derechos y obligaciones, o solo la legítima debería extraerse del activo de la herencia.

Entendemos que la legítima, y la obtención de la cuota legitimaria, implican no solo trabajar con el caudal relicto (los bienes, derechos y obligaciones que aparecen a la muerte del causante) sino que hay que ir a una reconstrucción del patrimonio hereditario, como más adelante detallamos.

Para empezar, al caudal relicto se le debe deducir el pasivo si fuere el caso, y a la renta neta debe sumársele las liberalidades otorgadas en vida del causante, si en efecto éstas se hubieren realizado, todo ello nos da un acervo imaginario como señala la legislación chilena.

Con este patrimonio reconstruido recién podremos obtener las cuotas legitimarias, si ello es así, entonces merece crítica que el legislador, cuando alude a la legítima, en los numerales del 725 al 727 del CC, se refiera solo a los bienes, sin embargo, ello no nos debe llevar a la conclusión de que en nuestra legislación la legítima no es pars hereditatis.
La legítima es pars hereditatis porque constituye parte del patrimonio que fue del causante, y que a propósito de su deceso se transmite a sus sucesores, empero consideramos que el patrimonio del cual van a obtenerse las cuotas legitimarias no debe considerarse exclusivamente el que encontramos a su deceso (caudal relicto), y ello por varias razones.

El patrimonio del causante, para los efectos sucesorios, no debe limitarse a los bienes y derechos que aparecen a la muerte del causante, pues a ello debe deducirse el pasivo que tuvo el causante y ello responde a que sus acreedores tienen preferencia al liquidarse la sucesión sobre cualquier otro sucesor. En esa medida, una vez que se ha deducido el pasivo del activo, nos encontramos con una renta neta, la misma que es un referente, pero no el único, ya que el causante en vida pudo haber realizado liberalidades a favor de los llamados herederos forzosos (anticipos de herencia) o a favor de terceros ajenos al entorno familiar (para la aplicación del artículo 1645).

El valor de todas esas liberalidades debe reintegrase contablemente al patrimonio neto con el objetivo de respetar las cuotas hereditarias de los herederos de igual clase y condición, si se trata de los anticipos de herencia para los efectos de la colación, y si se trata de terceros, para conocer si ha habido un exceso en la liberalidad (artículo 1629 del CC).

Una vez reconstruido el patrimonio hereditario recién podemos obtener las cuotas legitimarias; ahora bien, en cuanto al pago de esas cuotas se pueden hacer en especie o, en su defecto, vendiendo los bienes de la herencia y cancelando la cuota legitimaria en dinero. Sin embargo, esta forma de cancelar la legítima no es un indicador de que ésta sea pars bonorum como lo menciona Lohmann (2013, 314), más aún no solo es legal, sino que termina siendo la más práctica. El numeral 859 del CC: refiere 
"Los bienes se adjudicarán en especie a cada uno de los herederos. De no ser posible el valor de las cuotas le será pagado en dinero".

Se sostiene que la legítima es un crédito que tendrían los legitimarios contra el patrimonio hereditario. Sobre el particular, si se quiere ver así, podría considerarse un crédito, pero ello tampoco justifica que eso lo convierta en pars bonorum, porque ese crédito al efectivizarse se hará con especies del patrimonio hereditario o, como ya se señaló, con dinero producto de la venta de un bien hereditario.

\section{Legítima nace en defensa de los familiares del causante}

Desde sus inicios sea por la querella de inoficiocidad del testamento o por la cuarta falcidia la legítima, siempre estaba dirigida a asistir a los descendientes del causante, incluso la colación, en esos tiempos, era conocida como la collatio descendentiun, en atención a la obligación del que había recibido una ventaja económica del causante y debería devolver el valor del bien a la masa hereditaria para los efectos de la reconstrucción del patrimonio y partir en términos de equidad; en ese entonces, los únicos obligados a colacionar eran los descendientes.

Todo ello conduce a que estamos ante una institución netamente familiar y donde los terceros ajenos al entorno familiar no tienen derecho alguno. Sobre el particular, resulta ilustrativa la mención que hace Manuel Bustos Lagos al señalar que la relación de la garantía institucional del derecho a la herencia con la protección de la familia supone la necesidad de vinculación familiar o parental de al menos parte del patrimonio hereditario (1994). Esta afirmación se hace por cuanto los que sostienen la teoría de que la legítima es pars bonorum, no dudan en señalar que el legitimario no necesariamente es heredero, e incluso otros señalan que los legitimarios no son herederos.

\section{4. ¿Qué opina la doctrina sobre la legítima pars bonorum?}

Quienes sostienen que la legítima es pars bonorum la definen de la siguiente manera "La ley concede al legitimario un simple derecho de crédito puramente personal, a pagar en dinero, por una cuantía que se determine según la participación que se le reconozca en el valor del caudal. Por tanto, el legitimario no es heredero ni legatario, sino un simple titular de un crédito, pagadero en dinero por el importe de su legítima" (Pérez Gallardo X, 75).

Otros al referirse a la legítima pars bonorum, la definen "como parte del activo líquido, pudiendo recibirla los legitimarios por cualquier título, donación o legado, y no necesariamente en concepto de heredero, con derecho a que recaiga sobre bienes integrantes de la herencia" (Bercovitz 2009).

En Perú, con referencia a la legítima debemos considerar que Lohmann Guillermo es partidario de la legítima pars bonorum, no solo por la crítica que hace de la definición de la legítima en el código civil sino por las afirmaciones que sobre el particular emite, así nos dice "no todos los legitimarios son herederos", "la legítima es de derecho sucesorio, pero no necesariamente es de derecho hereditario, menos aún forzoso", "la legítima no siempre es parte del conjunto universal que el causante transmite, ni siempre tiene que ser satisfecha a título de herencia, porque de hecho el ordenamiento permite que pueda satisfacerse a título diferente del de heredero, y no necesariamente se paga con bienes incluidos en la herencia que el causante deja al fallecer" (2003, 315-319).

Pérez Lasala a propósito de la legítima en el derecho romano señala que "Justiniano en su novela 115 , modificó profundamente la orientación pars bonorum de la legítima, al exigir que las cuotas legitimarias fuese dejada a título de herencia y no por un título cualquiera" $(1989,782)$.

De las opiniones de los juristas citados, podemos señalar que la legítima pars bonorum, debemos entenderla en el sentido que puede ser otorgada por vía distinta de la herencia, es decir, entregarla en vida del causante. En 
Benjamín Aguilar Llanos

este supuesto no tendríamos que referirnos a herencia alguna porque el causante no ha fallecido y por ende no hay herencia.

Asimismo, se puede entregar la legítima en legados, en ese supuesto entonces no estaríamos ante herederos que por esa condición reciben la legítima, sino que lo estarían recibiendo como legatarios, situación diferente al heredero, que como conocemos no sustituye al causante, sino que viene a ser como sucedía en el derecho romano, un acreedor de la herencia respecto del bien objeto del legado.

En este supuesto se dice que la legítima es pars bonorum, por cuanto no lo reciben los herederos, sino incluso toda la legítima puede darse en calidad de legados y no de herederos.

Sobre el particular, y con cargo a comentar más extensamente, diremos que aún en esos supuestos quienes terminan recibiendo la legítima son los herederos. En el primer supuesto, cuando se alude a otorgar la legítima en vida del causante, los beneficiarios en efecto no son herederos, empero lo serán cuando se abra la sucesión del causante, tal como lo señala el artículo 831 del CC a propósito del anticipo de herencia. En el segundo supuesto, cuando se recibe la legítima como legados, igualmente lo estarían recibiendo los familiares del causante, parientes que como sabemos son en última instancia a los que la ley quiere proteger.

\section{5. ¿Los legitimarios no necesariamente son herederos?}

Responder a esta pregunta nos lleva precisamente a hacer un análisis si es que la tesis de legítima pars bonorum tiene una base real y legal.

Los partidarios de la legítima como pars bonorum señalan que se trata de un crédito que tienen los legitimarios contra el patrimonio del causante, pudiendo efectivizarse en especies o en dinero, además señalan que no necesariamente el legitimario es heredero, y debemos entender ello, en función de que están considerando que si la legítima ha sido pagada en vida del causante no se trataría de herencia alguna en tanto que el causante aún sigue vivo, y como no podemos hablar de sucesión de persona viva no podemos señalar que los que están recibiendo bienes o derechos del causante, lo estén haciendo en calidad de herederos.
Sobre la afirmación de que el causante pudo haber pagado la legítima en vida tenemos serias discrepancias, no tanto porque ello no resulte factible, más aún el CC prevé esta figura y la denomina anticipo de herencia (artículo 831 del CC), empero cuando fallece el causante, el valor de esos bienes o derechos que fueron anticipados se considerarán como un adelanto de lo que corresponde al anticipado, derivándose luego de esta figura la institución de la colación.

Más aún, cuando el causante en vía de liberalidad termina pagando las cuotas legitimarias a favor de los llamados herederos forzosos, como suelen decir los partidarios de la legítima pars bonorum, estas cuotas estaban referidas sobre el valor de los bienes que tenía el causante cuando efectuó la liberalidad, sin embargo, para el Derecho Sucesorio en lo que atañe al valor de los bienes que en vida ha dispuesto, es el valor de los bienes que tiene cuando ocurre su deceso.

Al abrirse la sucesión del causante, momento en el cual los bienes, derechos y obligaciones se transmiten a sus sucesores, debemos entender ello no solo refiriéndolo a las liberalidades que el causante otorgó en vida, sino igualmente a los bienes y derechos existentes a su muerte. Ahora bien, ese patrimonio causado debidamente reconstruido corresponde a sus herederos forzosos, siempre dentro de los límites que establece la ley, ello independientemente de que el testador haya hecho uso de su derecho de destinar su cuota de libre disposición a favor de terceros, pero en ese caso no estamos refiriéndonos a legitimarios, sino a legatarios.

El error según nuestro parecer parte de suponer que cuando el causante en vida otorga una liberalidad, para los defensores de la legítima pars bonorum esta liberalidad es una forma de pagar la legítima. Entonces, estos herederos forzosos ya no deberían 
participar del caudal relicto, y la pregunta es por qué, si siguen siendo herederos legitimarios, pero ahora sobre el caudal relicto.

Debe tenerse presente que para el Derecho Sucesorio lo importante y trascendente es el momento de la muerte del causante, allí recién podemos hablar de herederos, legatarios, pero antes no porque no hay sucesión de persona viva. Entonces, lo que pudo haber dado el causante a sus herederos forzosos en el momento que los otorgó no era a título de herencia y, por ende, no se estaba pagando legítima alguna, la cual recién cobrará vigencia, al abrirse la sucesión del causante. Cierto es que el valor de esos bienes dados en vida del causante no se ignora, al contrario, la misma ley señala que al ocurrir la muerte del causante, el valor de esos adelantos se considerará como anticipo de herencia.

\section{Según los partidarios de la legítima pars bonorum el legitimario no necesariamente es heredero o aún más categórico, el legitimario no es heredero}

Tratando de entender a quienes sostienen ello, trazamos un imaginario en el que el causante en vida ha cancelado las cuotas legitimarias de sus herederos forzosos y, en esa situación, ellos ya no tendrían derecho alguno sobre el caudal relicto, entendiéndose este caudal como los bienes y derechos que aparecen a la muerte del causante. De esa forma, se estaría en la idea que en razón de que el causante ya cumplió con el pago de las legítimas, entonces está libre de llamar en su testamento a herederos a quienes los termina beneficiando económicamente, y surge en éstos un derecho de crédito sobre ese patrimonio dejado por el causante, y estos derechos serían las cuotas legitimarias a los que harían tal referencia los que sustentan que el legitimario no es heredero. Si ello fuera así, quizás tendrían alguna razón, en cuanto a que estos herederos en efecto tienen un crédito que sería la cuota fijada por el testador, crédito sobre el caudal relicto.

Sin embargo, y ahora a la luz de nuestra legislación ello no se condice con la naturaleza jurídica de lo que es la legítima por varias razones. En primer lugar, tal como ya se ha mencionado la legítima existe en función de garantizar a los familiares cercanos y directos del causante, posibilitando su participación en la herencia que deja el causante, y en el escenario trazado quienes estarían participando del caudal relicto o son familiares lejanos del causante (hermanos, tíos sobrinos, sobrino nieto, tío abuelo) o son extraños a él.

En segundo lugar, porqué las cuotas legitimarias se van a obtener del patrimonio hereditario reconstruido, en el cual no solo se va a computar el caudal relicto sino igualmente se tomarán en cuenta las liberalidades otorgadas a favor de los herederos forzosos (y si fuera el caso a los otorgados a terceros) y recién con ese total que es contable, se aplicarán las cuotas, pero ello implica que los que recibieron en vida del causante su supuesta "cancelación de cuotas legitimarias" tengan que regresar el valor de esas liberalidades por cuanto la ley está considerándolos como anticipo de herencia.

En tercer lugar, porque la existencia de los llamados herederos forzosos impide la designación, que en este caso, sería de los voluntarios (artículo 737 del CC), entonces si el testador pensando que ha cumplido con el pago de la legítima en vida, designa herederos voluntarios, éstos a la luz de nuestra ley serán tenidos como legatarios, y su participación estará encuadrada dentro de la cuota de libre disposición (el error del testador en la denominación de uno u otro, alude a herederos o legatarios, no modifica la naturaleza de la disposición artículo 735).

Nuestra posición con normas de la legislación peruana es que no pueden coexistir herederos forzosos con voluntarios, y ello responde a que la legítima es exclusiva y excluyente, y en esa medida no es posible considerar a un heredero voluntario (en el caso de que no hubiera forzosos) como un legitimario, porque como ya se ha sostenido en forma reiterada los voluntarios responden al llamado que hace el testador. Él les da vida, y constituye un acto de liberalidad, mientras que el forzoso debe su derecho a la ley y toca al testador 
Benjamín Aguilar Llanos

respetar esas normas. Por lo tanto, resulta erróneo designar a legitimarios no herederos o que un heredero forzoso no sea un legitimario, sobre esto último, es posible que el forzoso pierda su condición de tal solo por causas debidamente establecidas en el código (indignidad, desheredación, renuncia).

\section{7. ¿La legislación vigente sobre la legítima admite la posibilidad de que los legitimarios no sean herederos del causante?}

Responder a esta pregunta, implica desarrollar una serie de conceptos que a continuación mencionamos.

7.1. Quienes son herederos forzosos para la ley peruana Con la anotación que hemos hecho sobre la denominación de forzosos señalamos que los legitimarios necesariamente son los descendientes, en su defecto, los ascendientes del causante, su cónyuge o si fuera el caso el sobreviviente de la unión de hecho. Incluso para que estos familiares cercanos del causante tengan derecho a la legítima, la misma ley peruana pone condiciones, como por ejemplo que los descendientes tengan el título de tal, es decir que la relación paterno filial esté debidamente establecida, tan es así que no cuenta como legitimario el llamado hijo alimentista del artículo 415 del CC por no haberse establecido esta relación.

En el caso de los ascendientes no necesariamente todos son legitimarios. Esto sucede cuando los padres del causante lo son por declaración judicial de paternidad (artículo 412 del $\mathrm{CC}$ ) o los han reconocido cuando el hijo era mayor de edad (artículo 398 del CC). En el caso de la cónyuge, para que lo sea, debe existir el matrimonio cuando se abre la sucesión del causante, impidiéndole participar de la herencia y en consecuencia no gozar de la calidad de legitimaria cuando al fallecer el causante se encontraba separada de él por su culpa (artículo 343 del CC).

Entonces, no les basta a los descendientes, ascendientes o cónyuge serlo, sino que no deben encontrarse en ninguno de los supuestos mencionados porque terminarían perdiendo su calidad de herederos y con ello la calidad de legitimarios.

Observamos cómo estos legitimarios son familiares muy cercanos del causante y en razón de ello y porque la legítima termina cumpliendo un papel asistencial es que se les considera con derecho a participar de una parte del patrimonio del causante.

No todos los familiares del causante tienen derecho a la legítima. Un claro ejemplo de ello lo vemos con los parientes colaterales, entre los que encontramos a los hermanos, tíos sobrinos, primos hermanos, tío abuelo sobrino nieto, todos ellos que por disposición del artículo 236 del CC tienen parentesco con efectos jurídicos, empero en el caso de la legítima no se les considera para ello.

\subsection{Para ser legitimario tiene que ser} necesariamente herederos del causante.

Hemos referido que los códigos de Chile y Colombia señalan que los herederos son legitimarios, ahora bien, nuestro $\mathrm{CC}$ no tiene una afirmación categórica como lo tienen esos códigos, más se pronuncia por señalar quienes son los legitimarios (artículo 724 del CC) y así nos dice que estos son los hijos y demás descendientes, los padres y demás ascendientes, el cónyuge y ahora, por ley 30007, también lo es el sobreviviente de una unión de hecho (concubino/a). Si a ello sumamos lo que dispone el artículo 816 del $\mathrm{CC}$, señalando los seis órdenes hereditarios donde aparecen en los tres primeros órdenes, los descendientes, ascendientes y cónyuge, vamos a concluir que en efecto en Perú para referirnos a los legitimarios estamos considerando a los que son herederos del causante. Entonces, hay una suerte de identificación entre legitimarios y herederos.

Esta identificación se justifica, si apelamos a los argumentos donde descansa la legítima, como un soporte económico a los integrantes del grupo familiar, participación directa o indirectamente de los familiares en la formación del patrimonio y, además, encontramos que la legítima termina cumpliendo una función alimentaria luego de fallecido el causante. 
El Derecho Sucesorio está concebido sobre la base de proteger a la familia, impidiendo que el patrimonio salga del entorno familiar, salvo en los casos donde no hay herederos forzosos. Sin embargo, en un solo caso el Derecho Sucesorio termina protegiendo a un tercero no heredero, y ese es el caso del llamado hijo alimentista, aquel que no ha sido reconocido ni declarado judicialmente, pero existe una presunción de paternidad solo con efectos alimentarios por haberse probado que un varón tuvo trato íntimo con la madre del llamado alimentista en la época de la concepción. Si ese varón es nuestro causante, el derecho familiar y sobre todo el Derecho Sucesorio se ocupan de este caso, donde las normas de sucesión terminan protegiendo al denominado hijo alimentista pese a que reconocen que no es heredero del causante.

Allí están los artículos 417 del CC estableciendo una obligación de los herederos del causante para cubrir los alimentos de este extramatrimonial, el artículo 728 del CC señalando la afectación de la cuota de libre disposición ante la existencia del hijo alimentista.

Lo que significa que, si el testador hubiera instituido un legatario para beneficiarlo económicamente, su legado se ve amenguado o quizás desaparecido porque primero se debe cumplir con los alimentos del alimentista y, por último, el artículo 874 del CC señalando que esos alimentos son deuda de la herencia, lo que implica que, como tal, primero deben ser satisfechos esos alimentos.

En conclusión, desde nuestro punto de vista no tiene asidero considerar a un extraño con respecto al causante como legitimario, porque no es heredero de él, porqué no se justificaría que la ley lo proteja, porque la ley protege a los familiares legitimarios, pero no a extraños.

Ello no significa constreñir, limitar al causante quien si desea favorecer a un extraño puede hacerlo en vía testamentaria usando su cuota de libre disposición, pero aún en ese caso este extraño que tendrá la calidad de legatario nunca podrá ser legitimario.

Además, como ya lo hemos manifestado, si el causante no tiene familiares con la calidad de herederos forzosos, entonces tiene libertad irrestricta para disponer de su patrimonio como mejor le parezca, y puede instituir herederos voluntarios que no tienen que ser familiares del causante. El causante puede dejar los bienes que integran su patrimonio en legados y para ello llamar a los legatarios no familiares del causante.

\section{Legítima es pars hereditatis porque incluye solo a los sucesores del causante}

Interesa desarrollar este tema, en tanto que los partidarios de la legítima pars bonorum afirman que no necesariamente el legitimario es heredero, e incluso van más allá al afirmar que los legitimarios no son herederos, ergo los legitimarios podrían ser extraños a la sucesión.

Hemos mencionado que los códigos de Colombia y Chile al definir a la legítima. Estos terminan señalando que los legitimarios son herederos, posición que compartimos y que a continuación desarrollamos.

$\mathrm{Si}$ el causante tiene herederos forzosos, se pone en movimiento la legítima. Ahora bien, como sabemos los llamados herederos forzosos son los descendientes, ascendientes y cónyuge del causante o, en su defecto, sobreviviente de la unión de hecho. Es de notar que todos ellos son familiares del causante, sea por parentesco (descendientes, ascendientes) o por matrimonio o por concubinato $y$, en todos estos casos, la protección va hacia ellos como una suerte de asistencia familiar basada en la solidaridad familiar.

Si el causante no tiene herederos forzosos, no tiene aplicación alguna la legítima, porque en ese supuesto estamos ante una libertad irrestricta de testar, pudiendo el causante instituir herederos voluntarios o legatarios. Es de observar que la ley protege a los legitimarios, más cuando no los hay, entonces el causante es libre de disponer de su patrimonio como mejor le parezca. En una situación de esa naturaleza no hay restricción 
Benjamín Aguilar Llanos

alguna a la facultad de disponer a título de liberalidades el bien o bienes que le pertenecen.

Dentro de este orden de ideas, nos preguntamos dónde se ubican los terceros legitimarios. El artículo 737 del CC señala que a falta de herederos forzosos se pueden instituir uno o más herederos voluntarios, empero aquí el testador no tiene limitación legal alguna y puede disponer de su patrimonio como mejor le parezca. Si instituye herederos voluntarios, está facultado para establecer la parte del patrimonio que les otorga, sino todo el patrimonio, y si ello no hubiera ocurrido, la misma ley se encarga de establecer que todos los herederos voluntarios recibirán cuotas iguales.

Estos herederos voluntarios pueden ser cualquier persona ajena al entorno familiar, e incluso parientes que no tienen la calidad de herederos forzosos, tales como los parientes colaterales del causante. Sin embargo, en ningún caso se les puede llamar legitimarios en tanto que las porciones o cuotas que reciban lo hacen en mérito al llamado que hace el testador para beneficiarlos económicamente.

Empero, dentro de los límites no de la ley, sino de la voluntad del testador, quien es el que pone límites si lo cree pertinente; entonces, estos derechos hereditarios nacen de la voluntad del testador cuando no existen los llamados herederos forzosos, por lo tanto no cabe hablar de legitimarios no forzosos, pues ello entraña una contradicción.

Señalar que los legitimarios no necesariamente son herederos ni mucho menos forzosos es desconocer el fin de la legítima, esto es su razón de su existencia y si a ello sumamos el hecho de que el Derecho Sucesorio se concibe como un derecho que cumple con garantizar el soporte económico de la familia, tal como lo refiere Delia Revoredo "en cuanto a su orientación este libro (sucesiones) del proyecto está inspirado en el concepto de que el derecho de sucesiones debe cumplir principalmente una función económica de protección familiar" (1980, 682).

Entonces vamos a concluir que necesariamente al referirnos a los legitimarios estamos comprendiendo dentro de ellos a los herederos forzosos. Cierto es que se presta a confusión la denominación que se da a los legitimarios al llamarlos herederos forzosos, porque invita a la confusión al pensar que esos herederos forzosamente tienen que serlo por mandato de la ley. Eso no es así, pues estaríamos desconociendo el ius delatione, la opción de todo sucesor de aceptar o renunciar una herencia.

\section{Legítima, normas de orden público}

El artículo cuarto de la Constitución alude al deber del Estado de defender la familia y en atención a ello, la mayoría de las normas que tenga referencia a los derechos de la familia o a los integrantes de la misma deben ser normas de obligatorio cumplimiento, sin la menor posibilidad de dejar al arbitrio de la persona su cumplimiento o no. En este orden de ideas se ubica la legítima como una institución que protege a los familiares cercanos del causante, reservándoles una parte del patrimonio, estableciendo además la obligación del causante de cumplir con esta reserva y si no lo hace, entonces, se regulan normas para revertir la situación.

La institución legitimaria existe en función de proteger a los familiares del causante, por ello no hay la mínima posibilidad de que se pacte contra la legítima, o se deje de cumplir ella. Repárese que todo está en función de estos parientes cercanos y directos del causante a quienes la ley protege llamándolos herederos forzosos. Entonces, si ello es así, cómo ubicar a legitimarios no parientes del causante gozando de la legítima, como se pretende a propósito de la tesis legítima pars bonorum.

Queda claro que las normas imperativas, en el derecho de familia, son para proteger derechos fundamentales de los integrantes del grupo familiar y dentro de ellos nos encontramos con la legítima, que si bien es cierto se regula en el Derecho Sucesorio, empero su base la encontramos en el derecho de familia, institución a la cual por mandato de la Constitución el Estado está en el deber de protegerla.

EI Derecho Sucesorio descansa principalmente en el derecho de familia y, en particular, en el 
parentesco. Por ello, en la sucesión intestada establece seis órdenes de herederos legales. Todos ellos a excepción del cónyuge o, si fuera el caso, el sobreviviente de la unión de hecho tienen nexo familiar. La institución legitimaria, que se aplica tanto en sucesión intestada como la testada, establece tres tipos de legitimarios.

Nuevamente, todos ellos, salvo el cónyuge supérstite o sobreviviente de la unión de hecho, descansan en el parentesco de los herederos con el causante. Entonces, podemos inferir que el Derecho Sucesorio defiende a los integrantes del grupo familiar, no a extraños a la familia; empero, cuando no hay estos legitimarios, en sede testamentaria, el causante puede convocar a título de herederos voluntarios a uno o más o, si fuera el caso, puede instituir legatarios adjudicándoles bienes específicos.

\section{La institución de la colación y la legítima}

La colación prevé un anticipo de herencia que implica liberalidades otorgadas por el causante en vida a uno (pueden ser más) de sus herederos forzosos, los cuales serán consideradas como un anticipo de herencia al fallecer el causante. El fin de la institución no es otro que aquel que recibió una ventaja económica no termine recibiendo más que otro heredero de la misma clase y condición. Por ello, el valor de la liberalidad regresa contablemente a la masa hereditaria para reconstruir ese acervo sucesorio, y entonces se le imputará a la cuota del que recibió la ventaja económica lo que importase el valor del anticipo, permitiendo con ello que todos los herederos forzosos reciban cuotas iguales.

Si ese es el fin de la colación, que la división de la herencia entre herederos de igual clase y condición se haga en términos de equidad, por tratarse de herederos del causante que están en una misma situación, entonces cómo se condice ello con terceros ajenos al entorno familiar para quienes según la tesis de la legítima pars bonorum los legitimarios no necesariamente tienen que ser herederos del causante, e incluso pueden serlo personas ajenas al entorno familiar del causante.

Si fuera el caso que el causante hubiera otorgado una liberalidad a un "legitimario no heredero" y en la sucesión, existieran los llamados herederos forzosos, esa liberalidad otorgada al legitimario no heredero no podría colacionarse en tanto que según nuestra legislación tiene establecido claramente quienes son los herederos forzosos. Solo entre ellos cabe el anticipo de herencia y, por ende, la colación. En el supuesto comentado esa liberalidad al tercero no legitimario debería encuadrarse dentro de los alcances del artículo 1629 del CC, es decir, "nadie puede dar por vía de donación más de lo que puede dar por testamento" complementado con el artículo 1645 del CC que alude a que si las donaciones exceden la porción disponible de la herencia se suprimen o reducen en cuanto al exceso, por cuanto ese exceso termina afectando a los herederos forzosos. Es de observar que según legislación peruana no cabría colación alguna entre los llamados legitimarios no herederos. Concluyendo con el tema de la colación, sería una razón más para señalar que dentro de nuestro sistema jurídico no es posible que los legitimarios no terminen siendo herederos del causante.

EI CC no ha dejado de regular a los herederos no forzosos y lo vemos en el artículo 816 del $\mathrm{CC}$ al referirse a los parientes colaterales del causante. Asimismo, regula a los herederos no parientes del causante y los denomina herederos voluntarios, empero para que ellos tengan presencia no deben existir los herederos forzosos, tal como expresamente lo establece el artículo 737 del CC. Es decir, no existe la mínima posibilidad de coexistencia de herederos forzosos con voluntarios y ello tiene mucho que ver con las características que tiene todo heredero, así como la legítima que termina siendo exclusiva y excluyente, y esta última característica está relacionada a la calidad de herederos forzosos, es decir al parentesco cercano y directo que tienen con el causante.

\section{A manera de conclusión}

a) La institución legitimaria tiene como fin proteger a los familiares cercanos $y$ 


\section{Benjamín Aguilar Llanos}

directos del causante, por ello no todos los parientes son legitimarios. Lo serán los más cercanos y directos como son los descendientes, ascendientes y cónyuge o, si fuera el caso, el sobreviviente de la unión de hecho.

b) En nuestro sistema jurídico, el fin de regular la sucesión en general (y en particular la legítima) es garantizar el soporte económico de la familia.

c) La legítima está regulada en el Derecho Sucesorio como una institución aplicable tanto a la sucesión legal como a la sucesión testamentaria. En cuanto a lo primero, obsérvese que solo pueden ser herederos los parientes del causante, salvo el caso del cónyuge o concubino(a) y, en lo segundo, solo pueden ser legitimarios los descendientes, ascendientes o cónyuge del causante, o concubino.

d) Es indudable la relación estrecha entre el Derecho Sucesorio y el Derecho de Familia. ello se demuestra al revisar a los herederos legales (sucesión intestada), donde quien no es pariente del causante no hereda, salvo el caso del cónyuge, siendo su fuente de herencia el matrimonio y en lo que atañe a la unión de hecho, el sobreviviente de esa unión descansa su derecho en la familia formada por esa unión estable y permanente. En la sucesión testamentaria, los llamados herederos forzosos son parientes del causante, así tenemos a los descendientes, ascendientes y el cónyuge o concubino con la anotación hecha.

e) La legítima es una porción de la herencia reservada a los llamados herederos forzosos, y éstos lo son los parientes cercanos y directos del causante.

f) El legitimario necesariamente tiene que ser familiar del causante.

g) Las cuotas legitimarias se obtienen luego del deceso del causante, reconstruyendo el patrimonio hereditario, deduciendo las deudas si las hubiere, adicionándose las liberalidades otorgadas en vida por el causante, y el resultado es el referente para obtener las cuotas legitimarias.

h) La ley peruana no deja de reconocer que el causante puede otorgar liberalidades a sus herederos forzosos y le da un tratamiento de anticipo de herencia, cuando se abra la sucesión del causante para los efectos de la colación.

i) Los partidarios de la legítima pars bonorum admiten la posibilidad de que la legítima sea pagada en vida del causante. Sobre el particular nuestra opinión discrepa con esa posición, sin embargo, no niega que pueda existir en la práctica que el causante haya entregado sus bienes a sus futuros herederos y se haya desprendido de todo su patrimonio. Si eso hubiera ocurrido y al abrirse la sucesión no existiera herencia alguna, diríamos que terminó pagándose la legítima. Sin embargo, si habiéndose otorgado liberalidades a los que mañana más tarde van a tener la calidad de herederos forzosos y al abrirse la sucesión del causante éste dejara bienes y derechos, entonces no puede darse por entendido que la legítima ha sido pagada en su totalidad, pues, esos herederos forzosos también tendrían derecho sobre esos bienes, porque lo principal en el Derecho Sucesorio es el momento en que se abre la sucesión, situación que permitirá saber con la reconstrucción del patrimonio si aún se debe legítima.

j) Los partidarios de la legítima pars bonorum señalan que la legítima puede ser cancelada no a título de heredero sino de legatarios, es decir, que a cada uno de los herederos forzosos se le entrega bienes en cancelación de su cuota pero bajo la figura de legados. Este supuesto en la normatividad peruana no cabe, porque los legados salen de la cuota de libre disposición y tienen un límite, precisamente esa porción disponible. Si el causante en su testamento distribuyera su herencia adjudicando bienes específicos a sus herederos, lo que no es raro, estaría pagando la legítima, tan es así que el CC lo regula en el artículo 852 a 
propósito de la partición testamentaria, cuando señala "no hay lugar a partición cuando el testador la ha dejado hecha en el testamento, pudiendo pedirse en este caso, solo la reducción en la parte que excede lo permitido por la ley". Es decir, si a un heredero en cancelación de su cuota se le ha adjudicado un bien cuyo valor no alcanza la cuota, se pedirá a otro heredero a quien se le adjudicó bienes superando su cuota que reduzca el exceso.

\section{Referencias bibliográficas}

Aguilar Llanos, Benjamín. 2014. Manual de Sucesiones. Lima: Instituto Pacífico.

Aliaga Castillo, César. 2007. Estudio de la colación en el ordenamiento sucesorio peruano, nueva perspectiva. Tesis para obtener el grado de abogado. Pontificia Universidad Católica del Perú.

Bercovitz Rodríguez-Cano, Rodrigo. coord. 2009. Derecho de Sucesiones. Madrid: Tecnos.
Bustos Lagos, Manuel. 1994. La garantía institucional de la herencia, derecho privado y derecho constitucional. Número 3: 29 - 62 .

Castañeda, Jorge Eugenio. 1975. Derecho de Sucesión, tom. II. Lima.

Lohmann Luca de Tena, Guillermo. 2003. Código Civil comentado, tom. IV.Derecho de Sucesiones. Lima: Gaceta Jurídica.

Polo Arévalo, Eva. 2013. Concepto y naturaleza jurídica de la legítima en derecho sucesorio español: precedentes y actualidad. Revista Internacional de Derecho Romano 10 (abril): 331-76.

Pérez Gallardo, Leonardo. 2015. Estudios sobre la legítima asistencial. Lima: Fondo Editorial del Colegio de Notarios de Lima.

Pérez Lasala, José Luis. 1989. Curso de Derecho Sucesorio. Buenos Aires: Depalma.

Revoredo, Delia. 1980. Proyectos y Anteproyectos de la Reforma del Código Civil, tom. I. Lima: Fondo Editorial PUCP. 